\title{
Endorsement of the HerniaSurge guidelines by the Australasian Hernia Society
}

\author{
H. $\operatorname{Tran}^{1}$
}

Received: 11 July 2017 / Accepted: 20 September 2017 / Published online: 12 January 2018

c) Springer-Verlag France SAS 2017

Since our inception in 2007, the Australasian Hernia Society has endeavoured to raise awareness of hernia surgery as a specialty. Indeed, we have organised numerous herniafocused meetings as well as running basic and advanced laparoscopic hernia repair workshops (provided free of charge by our Society), which have helped many surgeons upskilling in minimally invasive hernia surgery. Added to this the relatively high private health insurance rates have meant that patients take the lead in deciding the hernia repair techniques with high success rates, minimal morbidity and quicker return to normal physical activities.

Medicare Australia provides accurate figures on hernia repairs and laparoscopic hernia repair rates increased from 9.7\% in 1994 to over 54\% in 2016. Through our collaboration with the Department of Health and Ageing reviewing the practice of inguinal hernia surgery in Australia, we also discovered that the recurrence rate for inguinal hernia surgery has remained at $7.9 \%$ over the past 20 years. Clearly, despite massive advances in minimally invasive surgery and improvements in mesh prosthetics over the past 30 years, we are still failing our patients on these high failure rates.
Despite being some 16,000 km from most European cities, where HerniaSurge held up to three meetings per year between 2014 and 2016, our Society has attended every meeting and played an important role in regards to contribution to the formulation of the International Guidelines for Adult Groin Hernia Management. We are humbled to have been invited to contribute to these comprehensive guidelines under the leadership of Maarten Simons and some 50 world renowned hernia specialists. We are certain that general practitioners and surgeons will find these guidelines helpful in their daily practice wherever they come from. As always, our aim is for the betterment of patient care.

Hanh Tran, President Wayne Hawthorne, Secretary General Australasian Hernia Society

\section{Compliance with ethical standards}

Conflict of interest The author declares no conflict of interest.

This comment refers to the article available at doi:10.1007/ s10029-017-1668-x.

H. Tran

drdrmba@gmail.com

1 The Sydney Hernia Specialists Clinic, Level 2, 195

Macquarie St, Sydney, NSW 2000, Australia 